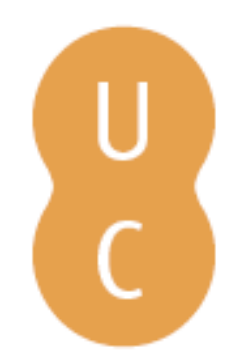

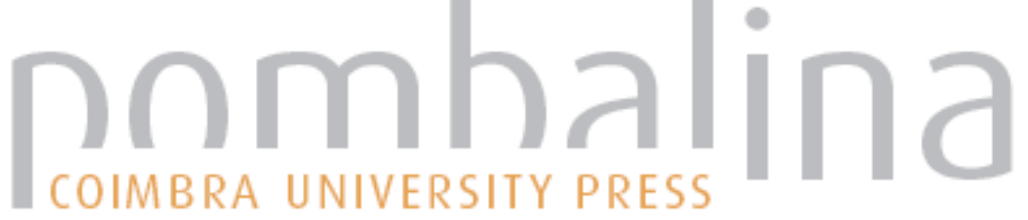

\section{As águas subterrâneas no concelho do Porto: um estudo hidro-histórico}

Autor(es): $\quad$ Devy-Vareta, N.; Freitas, L.; Gomes, A.; Afonso, M. J.; Chaminé, H. I.

Publicado por: Imprensa da Universidade de Coimbra

URL

persistente: URI:http://hdl.handle.net/10316.2/31207

DOI: $\quad$ DOI:http://dx.doi.org/10.14195/978-989-26-0244-8_97

Accessed : $\quad$ 26-Apr-2023 13:29:45

A navegação consulta e descarregamento dos títulos inseridos nas Bibliotecas Digitais UC Digitalis, UC Pombalina e UC Impactum, pressupõem a aceitação plena e sem reservas dos Termos e Condições de Uso destas Bibliotecas Digitais, disponíveis em https://digitalis.uc.pt/pt-pt/termos.

Conforme exposto nos referidos Termos e Condições de Uso, o descarregamento de títulos de acesso restrito requer uma licença válida de autorização devendo o utilizador aceder ao(s) documento(s) a partir de um endereço de IP da instituição detentora da supramencionada licença.

Ao utilizador é apenas permitido o descarregamento para uso pessoal, pelo que o emprego do(s) título(s) descarregado(s) para outro fim, designadamente comercial, carece de autorização do respetivo autor ou editor da obra.

Na medida em que todas as obras da UC Digitalis se encontram protegidas pelo Código do Direito de Autor e Direitos Conexos e demais legislação aplicável, toda a cópia, parcial ou total, deste documento, nos casos em que é legalmente admitida, deverá conter ou fazer-se acompanhar por este aviso. 


\section{TRUNFOS DE UMA}

\section{EOGRAFIA ACIVA}

\section{DESENVOLVIMENTO LOCAL,}

AMBIENTE,

ORDENAMENTO

E TECNOLOGIA

Norberto Santos

Lúcio Cunha

COORDENAÇÃO 


\author{
N. Devy-Vareta ${ }^{1,2}$, L. Freitas ${ }^{1}$, A. Gomes ${ }^{1,2}$, M. J. Afonso ${ }^{3,4}$, H. I. Chaminé, 3,4 \\ ${ }^{1}$ Departamento de Geografia da Faculdade de Letras da Universidade do Porto \\ ${ }^{2}$ Centro de Estudos em Geografia e Ordenamento do Território (CEGOT) \\ ${ }^{3}$ Laboratório de Cartografia e Geologia Aplicada, LABCARGA, Departamento de Engenharia \\ Geotécnica, Instituto Superior de Engenharia do Porto \\ ${ }^{4}$ Centro GeoBioTec, Universidade de Aveiro
}

\title{
AS ÁGUAS SUBTERRÂNEAS NO CONCELHO DO PORTO: UM ESTUDO HIDRO-HISTÓRICO
}

\section{INTRODUÇÃO}

O projecto GROUNDURBAN/FCT constituiu uma investigação multidisciplinar do recurso mais disputado no futuro da humanidade: a água.

Um relatório recente da ONU, apontou uma mudança importante para os finais de 2008, afirmando que o espaço urbano já concentraria metade da populaçáo mundial e estimando que este atinja os $70 \%$ em $2050^{1}$. Nesta perspectiva, a hidrogeologia em áreas urbanas reveste-se da maior importância, nomeadamente, no que diz respeito à recarga e circulação de águas subterrâneas que, a par das águas superficiais, constituem um dos pilares da sustentabilidade nas cidades e meios peri-urbanos (e.g., Afonso, 2003; Afonso et al. 2007, a, b; Carvalho \& Chaminé, 2007).

O que justifica o cerne da nossa investigação não se relaciona com objectivos meramente historicistas, nem com uma interpretação renovada dos recursos e usos das águas subterrâneas no passado da cidade. A opção pelo estudo hidro-histórico retrospectivo baseou-se na hipótese de que uma melhor percepção da evolução da quantidade/qualidade das águas subterrâneas, como da sua gestáo na superfície, podia abrir perspectivas interessantes para o conhecimento da situação actual do recurso água subterrânea, consolidando os estudos prospectivos. Aliás, esta postura participa num movimento internacional que reconhece a importância da abordagem multi e transdisciplinar da água, nomeadamente da história da sua utilizaçáo civilizacional, de modo a aperfeiçoar o estudo da conexão entre processos ambientais e sócio-económicos da sustentabilidade, em determinada escala espaço-temporal (Tempelhoff et al. 2009). Nesta perspectiva, a utilização de um SIG torna-se imprescindível, pois facilita o cruzamento de toda a informação, sugerindo pistas mais seguras na investigação.

No Porto, nascentes e mananciais, que se encontram nos limites actuais da cidade, constituíam a alimentação de fontanários, lavadouros e bebedouros para os animais até $1887^{2}$. Nesse ano, iniciou-se o abastecimento da cidade com as águas canalizadas do rio Sousa (Cordeiro, 1993). Mas a água de numerosos poços e fontes continuou a assegurar os usos

\footnotetext{
${ }^{1}$ World Urbanization Prospects: the 2007 Revision Population Database, http://esa.un.org/unup/.

${ }^{2}$ Neste trabalho a terminologia usada está de acordo com os vocábulos empregues em estudos hidrogeológicos: nascente ou fonte, fontanário, marco fontanário e chafariz. Os três últimos vocábulos referem-se à existência de uma infraestrutura.
} 
domésticos do povo portuense nas décadas seguintes, particularmente nos bairros mais pobres. Já nessa altura, o Porto era um centro urbano e económico de primeira grandeza no país. Desde a Idade Média, a cidade tinha densificado a sua expansão em torno dos morros graníticos da Penaventosa e da Vitória, separados pelo vale do Rio da Vila (Marques et al. 1990; Oliveira, 1973). No século XVI, o desenvolvimento da cidade mercantil abre um sério problema de abastecimento em água, resolvido então pelo aproveitamento do manancial de Paranhos. No início do século XVII, as águas de Paranhos chegam aos fontanários do centro da cidade por aquedutos de pedra e canos de barro (Silva, 1888). No século seguinte, reforça-se o crescimento da cidade com o comércio do vinho do Porto e empreende-se uma renovação urbana. Mas é sobretudo no século XIX que se verifica um forte aumento populacional nos tempos da industrialização (Ramos, 2000). Em 1864, o recenseamento da população regista perto de 87.000 habitantes; no de 1890, o número de habitantes é avaliado em cerca de 147.000 pessoas (INE, Recenseamento Geral da população). Por isso, as necessidades em água aumentam drasticamente, forçando a decisão do abastecimento por águas superficiais, tal como ocorre na maior parte dos centros urbanos do mundo ocidental (Bocquet et al. 2008). Ao mesmo tempo, despertam as preocupaçóes higiénicas que acompanham, em meados do século XIX, a urbanização crescente e as descobertas das relaçóes entre doenças e água (Geels, 2005).

Este trabalho apresenta inicialmente a metodologia seguida na construção da base de dados, a que se segue a apresentação de cartografia seleccionada que suporta a discussão de alguns problemas ligados aos recursos hídricos.

\section{Metodologia}

A realização deste estudo tem por base uma pesquisa bibliográfica e cartográfica focalizada no tema das águas subterrâneas do concelho do Porto, mediante a consulta de inúmeros documentos com informaçóes de variada índole, tais como: livros, teses, artigos, manuscritos e mapas antigos. Analisando a bibliografia publicada sobre o assunto nas últimas décadas, verificou-se que a maior parte dos estudos se baseiam, invariavelmente, em alguns documentos primários. Como tal, e de acordo com o objectivo do projecto, ou seja, apresentar resultados fidedignos, recorreu-se preferencialmente às fontes primárias para evitar redundância na informação. Entre as obras impressas, destacam-se por ordem cronológica: Estudo sobre o abastecimento d'agua da cidade do Porto (Gavand, 1964), As águas do Rio Souza e os mananciais e fontes da Cidade do Porto (Silva, 1881), As aguas do Porto (Bourbon e Noronha, 1885), Breves apontamentos sobre aguas de poços do Porto (Júnior, 1895) e, por fim, a fundamental Contribuição para a Hygiene do Porto: analyse sanitária do seu abastecimento em água potável, composta por três dissertaçôes, cuja temática se prende com as questôes da higiene muito em voga na época, apresentadas à Escola Médico-Cirúrgica do Porto no início do século XX, cada uma constituindo uma parte da obra global. A primeira estuda os mananciais de Paranhos e Salgueiros (Fontes, 1908), a segunda os mananciais do Campo Grande, Bispo e Freiras, Cavaca, Camóes, Virtudes, Fontaínhas, Praça do Marquês de Pombal e Burgal (Bahia Junior, 1909) e a terceira, os poços existentes na cidade da época (Carteado Mena, 1908). Do início aos finais do século passado, quase todos os trabalhos, quer de investigação quer de divulgação, referem-se a um manuscrito de consulta imprescindível, o Mappa synoptico, estatístico, historico dos mananciaes publicos d'esta Antiga, mui Nobre, sempre 
Leal e Invicta Cidade do Porto (Reis, 1867). Este inventário, empreendido pela Câmara do Porto nos anos de 1860, actualiza e integra outros anteriores, sendo contemporâneo da publicação da obra de Gavand (1864), no qual se aponta para a distribuição de água canalizada a partir da captação superficial das águas do rio Sousa.

Se por um lado a pesquisa bibliográfica demonstra a elevada relevância de algumas obras, por outro a procura de cartas antigas da cidade do Porto é fundamental para a futura georreferenciaçáo dos elementos provenientes das fontes primárias. Várias foram as cartas antigas analisadas, salientando-se: Cidade do Porto também chamada de "Planta Redonda" (Balck 1813); Porto (Clark 1833); Planta Topographica da Cidade do Porto (Lima 1839); Planta da Cidade do Porto (Perry-Vidal 1865); Carta Topographica da Cidade do Porto (Ferreira 1892); Contribuição para o estudo da hygiene do Porto: analyse sanitaria do seu abastecimento em água potável, Estudo sobre os poços do Porto (Carteado Mena, 1908).

Todos estes documentos bibliográficos e cartográficos, entre outros, foram inseridos numa base de dados criada através de um programa informático de gestáo bibliográfica que permite a realização de pesquisas online, a edição de referências e sua posterior inserção no formato de bibliografia, o software EndNote.

A análise desta bibliografia evidenciou uma diversidade de informação que poderia ser tratada e inserida num Sistema de Informação Geográfica (recorreu-se para isso ao software ArcGis 9.2), no qual se reuniram os dados espaciais do projecto. O ponto de partida deste sistema consistiu na inserção da base topográfica, geomorfológica, hidrogeológica e hidrológica superficial do concelho do Porto. No entanto, e de acordo com os objectivos do estudo, revelou-se fundamental a georreferenciação da informação proveniente da análise dos documentos bibliográficos e cartográficos recolhidos, como ilustra a figura 1. A referida informação permitiu a localização de mananciais, fontanários, chafarizes e topónimos relacionados com a hidrologia subterrânea e superficial da cidade do Porto.

$\mathrm{Na}$ georreferenciaçáo de todos estes elementos e entendimento da respectiva dinâmica espaço-temporal, foi necessário seguir metodologias diferentes (confronto bibliográfico e cartográfico, complementado com trabalho de campo), que resultassem numa georreferenciação correcta, dado que alguns elementos desapareceram ao longo do período estudado, facto que está perfeitamente documentado pela bibliografia. Deste modo, iniciou-se o processo de georreferenciação a partir dos elementos encontrados na actualidade. Para tal e de acordo com o objectivo de melhorar a precisão na localização dos mananciais de água existentes, realizou-se trabalho de campo para o reconhecimento e confirmação da existência dos fontanários e chafarizes. Durante o trabalho de campo foram tomadas anotaçóes relativas a cada elemento identificado e a sua localização através do Google Earth Pro. Após a marcação de todos pontos de água notáveis, foram registadas as coordenadas de cada um dos pontos obtidos, resultando um ficheiro com formato $\mathrm{Kml}$. Este permitiu uma certa inter-operacionalidade com outros programas informáticos, pois tornou-se fundamental transformar o ficheiro de dados obtido noutro, passível de ser utilizado em ambiente SIG, sendo este o formato shapefile do ArcMap, correspondente a um formato vectorial de armazenamento digital de dados, o qual agrega a localização de elementos geográficos aos atributos associados ${ }^{3}$.

Era nosso propósito que a localização dos fontanários e chafarizes destruídos, chamados históricos, teria igualmente de ser a mais precisa possível. Como tal recorreu-se às descriçóes

\footnotetext{
${ }^{3}$ A transformação dos ficheiros foi realizada através de um programa informático disponível em: http:// www.zonums.com/kml2shp.html.
} 
existentes na bibliografia sobre o tema (e.g., Marçal, 1968; Silva, 2000; Amorim \& Pinto, 2001). A terminologia utilizada, "históricos", justifica-se pelo facto destes já não existirem fisicamente, simplesmente resta a sua lembrança oferecida na bibliografia consultada. A sua georreferenciação, já em ambiente SIG, seguiu a metodologia anteriormente descrita. No entanto, surgiu outra dificuldade que se prende com a alteração da toponímia urbana, facto que facilmente se compreende pelo forte crescimento da cidade que decorreu no período em questão (Serén \& Pereira, 2000). Para ultrapassar esta dificuldade, revelou-se fundamental a georreferenciação das fontes cartográficas antigas.

Figura 5 - Poços na cidade do Porto inventariados no estudo de Carteado Mena (1908).

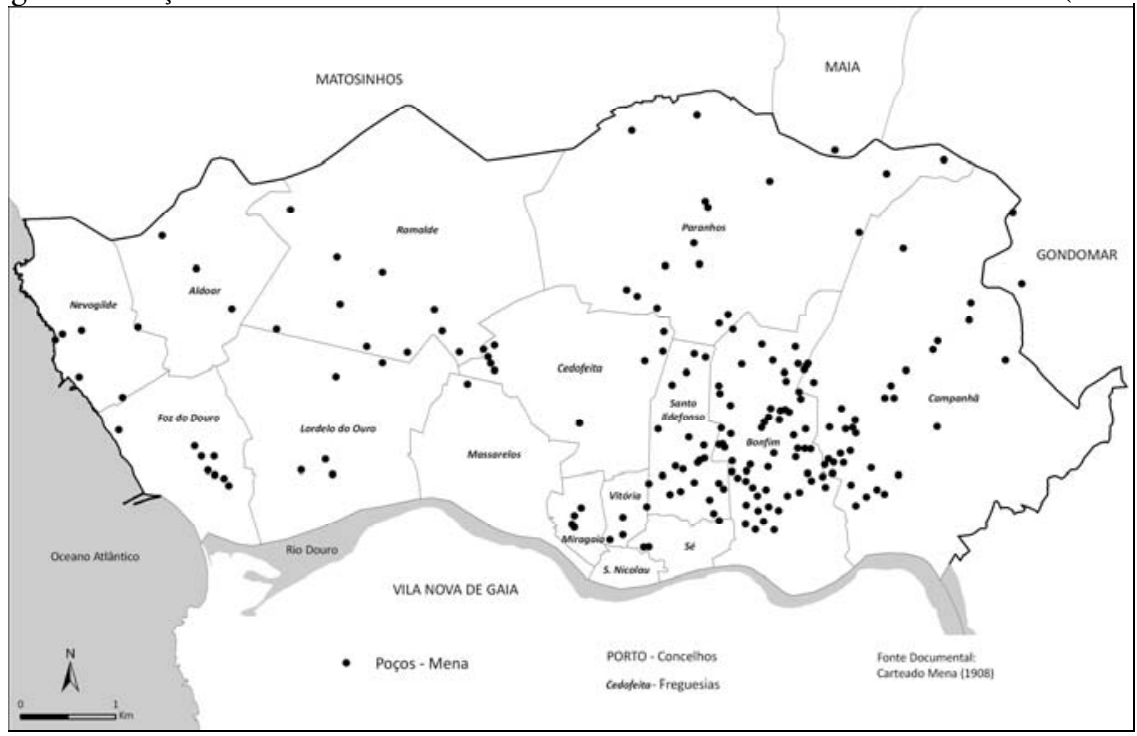

De acordo com os objectivos deste estudo, faltava ainda a georreferenciação da toponímia relacionada com a existência de água superficial e subterrânea, ou seja, a hidrotoponímia. Para tal utilizou-se a mesma metodologia, i.e., da actualidade para o passado. Dessa forma, analisou-se a base actual da toponímia do Porto e seleccionaram-se todos os topónimos relacionados com hidrografia e água em geral. Para obter os topónimos modificados ao longo do tempo recorreu-se, por um lado, à cartografia antiga (georreferenciada durante as actividades do projecto) assim como à Carta Topographica da Cidade do Porto (Ferreira 1892), confrontando, deste modo, as denominaçóes dos locais actuais com as do passado.

De uma forma sintética, a metodologia descrita anteriormente pode ser apresentada a partir do esquema patente na figura 2 que apresenta as várias fases do estudo.

\section{RESUlTADOS}

A distribuição espacial de todas as referências sobre nascentes, fontanários, chafarizes reflecte, de certo modo, a formaçáo da cidade nos limites actuais do concelho (figura 3). Os 
levantamentos realizados em 1908-1909 no âmbito da higienização da cidade revelam a mancha urbana do mapa de Telles Ferreira, com maior concentração de edifícios, de Oeste para leste, entre o Rio do Vilar - ainda bem marcado no mapa com um alinhamento de fontes e nascentes - o manancial de Salgueiros e o do Campo 24 de Agosto.

Figura 6 - Esquema metodológico do estudo desenvolvido

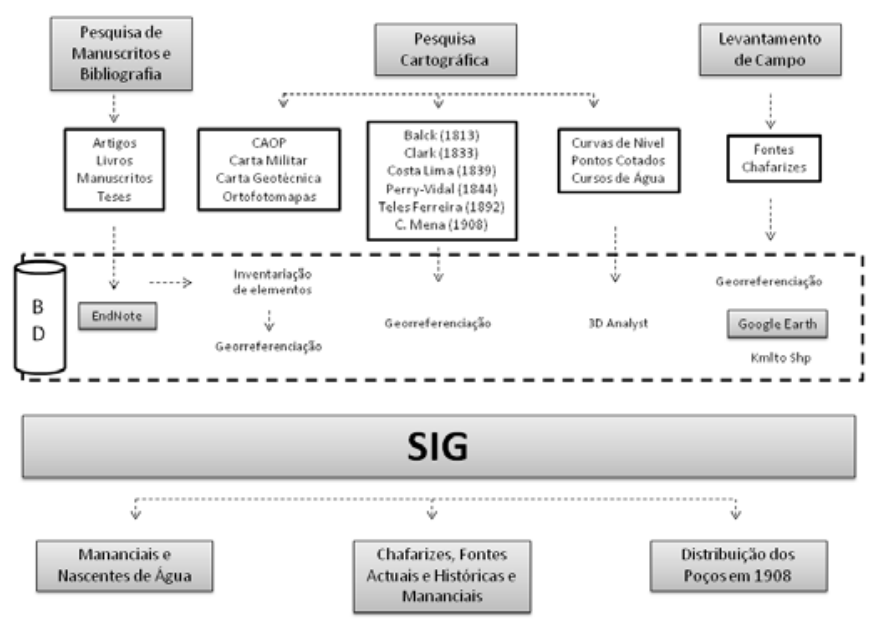

Ao longo das estradas e vias, antigas ou rasgadas há pouco, densificavam-se as construçôes. É no núcleo central da cidade que se regista na actualidade a maior proporçáo de fontanários desaparecidos ou removidos para outros locais. $\mathrm{O}$ alargamento da rede canalizada da "Água da Companhia" e a renovação urbana levou à destruição ou remoção de numerosos chafarizes e fontes alimentadas pelos mananciais públicos referidos na documentação. Apenas as águas de Paranhos, que chegavam às fontes do Porto desde o início do século XVII, misturadas com as de Salgueiros em 1838, circulam actualmente nas galerias subterrâneas da cidade.

Há cerca de 150 anos, os mananciais públicos, a maior parte localizada acima dos 80 $\mathrm{m}$ de altitude, e outras nascentes privadas forneciam a água das fontes no centro urbano. A quase totalidade dos fontanários com nascente própria hoje existentes, deixaram de ter água e somente algumas conservaram a sua função. Repare-se que nestas últimas, algumas já referidas na Idade Média, se encontram nas áreas topograficamente mais baixas da cidade, tais como a fonte da Colher em Miragaia, as da rua de D. Pedro V e do Caco (oriundas do Morro da Pena), da Cantareira (Foz do Douro) ou do Esteiro da Campanhá.

$\mathrm{Na}$ coroa de freguesias mais rurais, de Aldoar a Campanhã (figura 1), muitas fontes nascente náo tinham bica, mas brotavam nos campos ou nos casais, sumariamente abrigadas por pedras de granito. Os pontos de referência da documentação para a localização exacta destas fontes já não existem, apagados pela construção de edifícios e vias de trânsito. A hidrotoponímia, nomeadamente os nomes actuais e passados de lugares, vias e bairros, revela-se então muito útil para uma provável localização destas nascentes (figura 4). Talvez o facto de muitas fontes da periferia serem sumariamente empedradas justifique a elevada 
frequência de topónimos relacionados com nascentes, lamas e lameiros (46\%). Os toponimos vegetais, um terço do total, dizem sobretudo respeito às espécies arbóreas ripícolas, como o freixo, o amieiro e o salgueiro (figura 4).

Figura 7 - Mananciais e nascentes de água subterrânea para o abastecimento de água na cidade do Porto, nos finais do séc XIX.

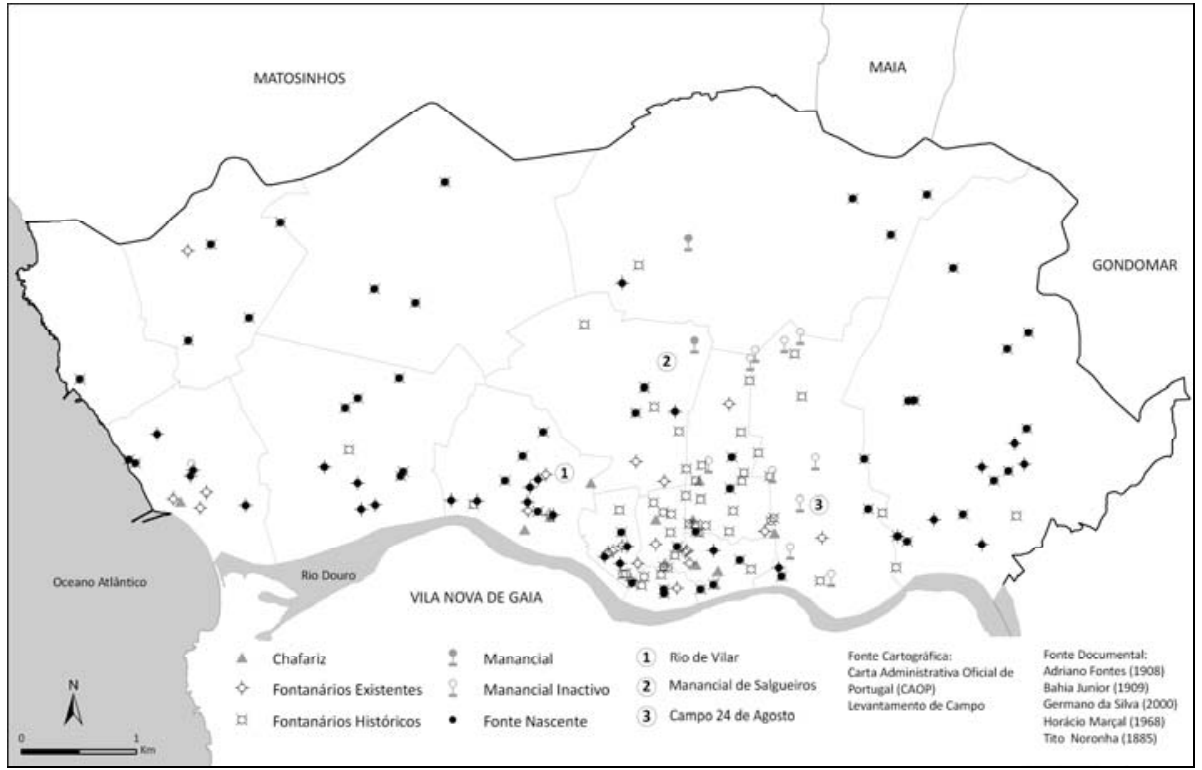

Figura 8 - Mapa dos hidrotopónimos da área urbana do Porto.

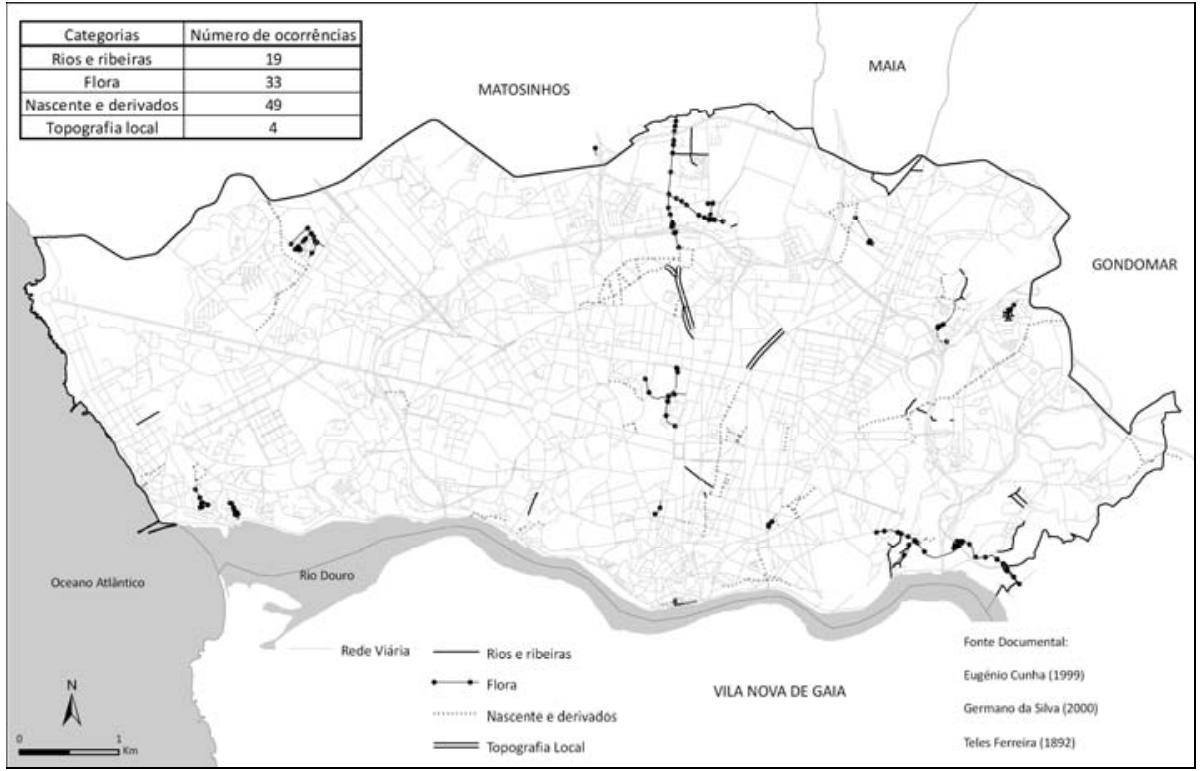


Em termos de localização, destacam-se três grupos: (1) os limites de Ramalde e Aldoar, a montante da bacia da Ribeira do Aldoar, com vários topónimos ligados à Fonte da Moura; (2) Paranhos, onde se localiza o carismático mananciall'; ; (3) por último, Campanhã, onde se encontram, de norte a sul, o grupo de Contumil - o manancial já desapareceu -, o conjunto de $S$. Roque da Lameira, com as nascentes que existiam na rua ou nas proximidades, e o conjunto do Freixo. Também em Campanhã há referências da existência de "águas termais", com o testemunho da rua das "águas férreas", nos limites orientais da cidade (Reis, 1867).

Nas freguesias mais antigas do Porto, permanecem na actualidade poucos topónimos ligados à água, excluindo as áreas com maior concentração de nascentes: bairro da Fontinha, a norte de Gonçalo Cristóvão, e as Fontaínhas. Verifica-se que a partir dos finais do século XIX, os hidrotopónimos foram geralmente substituídos por nomes de personalidades do mundo das letras ou do liberalismo.

\section{DISCUSSÃO}

Cerca de 1840, após um período de estagnação durante o primeiro terço do século, calcula-se que a população do Porto nos limites actuais da cidade contava cerca de 60.000 habitantes (Serén \& Pereira, 2000). Em pouco menos de cinco décadas (1864-1911), a população residente aumentou espantosamente, de 89.349 para 191.890 habitantes, correspondendo a um acréscimo de $114,5 \%$ em relação à população que existia no ano de 1864 , ano do I Recenseamento Geral da População. Este facto teve consequências a diversos níveis, nomeadamente sociais, económicos e espaciais, que se encontram intimamente relacionadas, pois o aumento da populaçáo levou a uma necessidade de resposta em termos de alimento, água, organização do trabalho e alojamento para a manutenção das famílias. Destas, salientamos particularmente as novas exigências no consumo de água, que começa a escassear face à procura deste recurso essencial para a vida de cidade 5 . Por outro lado, o limite da cidade ficou confinado às sete freguesias do actual centro até ao arranque do aumento populacional da segunda metade de século, e como consequência deste aumento, ocorreu o alargamento dos limites da cidade nos finais do século ${ }^{6}$.

O cálculo da variação da população neste período reflecte um aumento geral em todas as freguesias do concelho, embora não de forma homogénea. É de salientar a freguesia de $S$. Nicolau na qual se regista uma evoluçáo negativa da população, o que pode ser justificado pelas renovaçóes urbanísticas empreendidas no centro histórico. Note-se, aliás, que nesta freguesia, já com uma forte densidade de edifícios impossibilitando a sua expansão, não existe nenhum poço que possa facultar o acesso à água exigida pelo aumento da população (figuras

\footnotetext{
${ }^{4}$ De notar a riqueza da hidrotoponímia derivada do nome das aldeias ou quintas existentes na freguesia de Paranhos em meados do século XVIII, como Regado e Regueiras, Lamas, Azenha, Val e Aval (Capela, 2009).

5 Já em 1864, segundo E. Gavand "todas as fontes do Porto reunidas não dáo mais de 8 a 9 litros de água por dia e por habitante no verão" (p. 30), o que considera muito insuficiente. Cita alguns exemplos das quantidades distribuídas em cidades europeias, tais como Londres (112 l), Génova (110 l), Paris (90 l), Munich (80 l), Genebra (76 1) ou Madrid (70 l) (Gavand 1864; p. 23-24).

${ }^{6}$ Com as reformas administrativas do liberalismo de 1836 , a cidade estendeu-se ao longo do rio Douro, anexando Campanhã a leste, e Lordelo e Foz do Douro a oeste. Em 1837, agrega-se Paranhos à cidade, e finalmente em 1895, integram-se Ramalde, Aldoar e Nevogilde. A freguesia de Bonfim foi criada em 1841 com áreas de St. ${ }^{\circ}$ Ildefonso, Campanhã e Sé.
} 
1 e 5), isto de acordo com o levantamento realizado por Carteado Mena (1908). Segundo o mesmo levantamento, a metade oriental da cidade apresenta uma elevada densidade de poços correspondendo às freguesias que mais viram aumentar a sua população, nomeadamente Bonfim, Campanhã, Cedofeita e Paranhos. A distribuição dos poços parece acompanhar o traçado de vias, como S. Roque da Lameira na freguesia de Campanhá, locais onde se concentrava a população. Destaca-se nitidamente a freguesia do Bonfim pelo elevado número de poços inventariados, a qual se caracteriza por um aumento da população responsável por 19,7 \% do aumento total que se deu na cidade entre 1864 e 1911.

Figura 9 - Distribuição dos poços e variação da população em finais do séc. XIX e início do XX'.

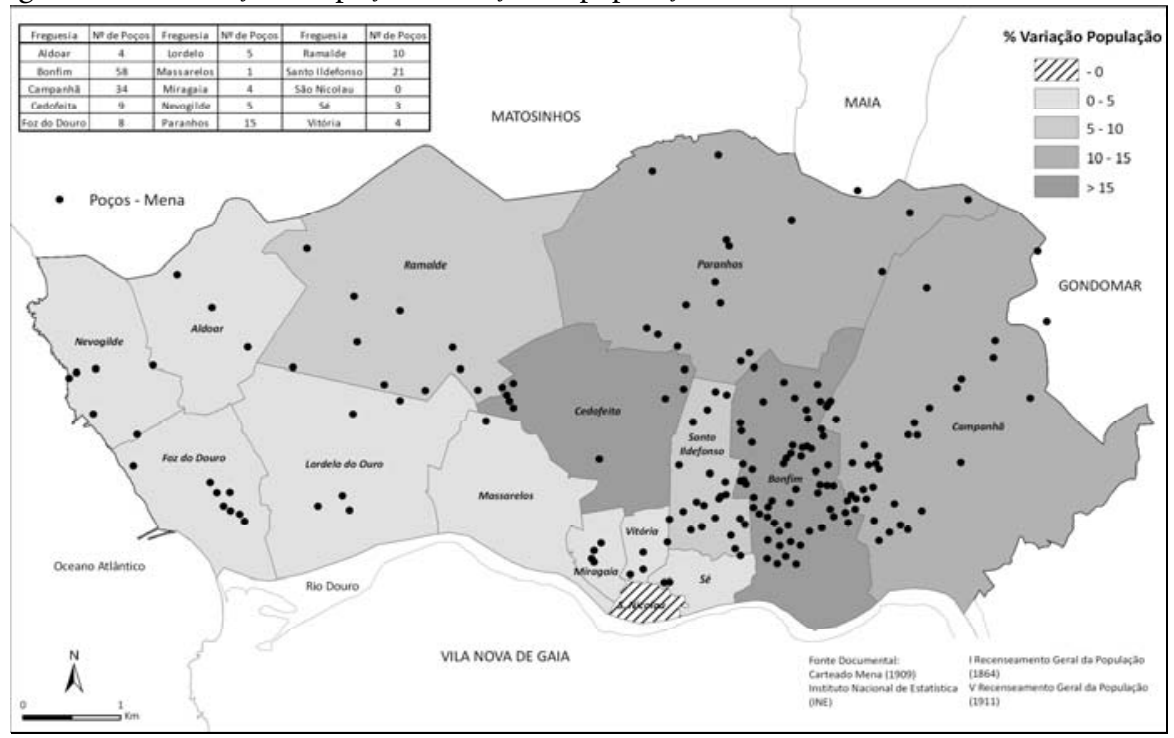

Nesta freguesia como em outras, na época, houve um surto industrial que justifica um explosivo aumento da população acompanhado pela densificação da mancha urbana. A existência da indústria nestes territórios favorece a contaminação das águas subterrâneas e superficiais, e como tal, a solução passa pela captação de águas subterrâneas a maiores profundidades procurando, por um lado, melhor qualidade e por outro maior quantidade. No entanto, a falta generalizada de saneamento e a escassez da água faz-se cruelmente sentir nas áreas mais sobrepovoadas marcadas pela pobreza. Na segunda metade do século XIX, a taxa de mortalidade ronda os 30 por mil, podendo ser ainda mais elevada nas ilhas, forma de alojamento popular que muito se desenvolve então. Calcula-se que cerca de um terço da população portuense vivia em ilhas por volta de 1900 (Serén \& Pereira, 2000). Enquanto se estendia a rede da água canalizada, fontanários e poços continuam a abastecer grande parte da população, propiciando o alastramento de epidemias de cólera, tifo e disenterias pela inquinação das águas (Silva, 1881; Jorge, 1888; Fontes, 1908). A sustentabilidade do georrecurso tinha atingido o ponto de ruptura com graves repercussóes na saúde pública.

${ }^{7} \mathrm{O}$ aumento da população por freguesia foi normalizado usando o valor de incremento total da população da cidade [Pop freguesia (1911-1864)/ Pop concelho (1911-1864)*100]. 


\section{CONSIDERAÇÓES FINAIS}

Os anos 1850-1880 foram cruciais para o problema da água na cidade do Porto, seguindo de resto, a mesma evolução das cidades do mundo ocidental (Bocquet e Chatzis, 2008): nascentes, sistema público de fontanários e poços até à criação de uma rede de abastecimento domiciliária e pública por captação superficial ou subterrânea. O problema da quantidade de água a fornecer é o mais premente em meados do século XIX e mantém-se nos dias de hoje tal desiderato, como evidenciam as investigaçóes hidrogeológicas da área urbana do Porto de Afonso et al. (2007). A proposta adiada de Gavand em 1864, para se efectuar o abastecimento com recurso às águas do Rio Sousa situa-se na transição para uma nova preocupação: a qualidade da água e sua relação com a saúde pública e a difusão de doenças. No Porto, a prática das análises bioquímicas terá um impacte decisivo no início da construção da rede de canalizações (Silva, 1881).

Não restam dúvidas de que o cruzamento de métodos que conduziu à base de dados ligada a um Sistema de Informação Geográfica (SIG) proporciona uma ferramenta de apoio à decisão para uma nova visão da questão da evolução da sustentabilidade das águas subterrâneas na cidade. Além do mais, evidenciou-se a importância do trabalho de campo para a construção de um modelo hidro-histórico com uma raíz geográfica e hidrogeológica. A abordagem histórica do abastecimento da água ultrapassa aqui os aspectos ligados à reconstrução da memória, mas permite explorar uma possível comunicação entre a hidro-história e os debates actuais sobre a gestão da água, que se situam na mesma interface entre sociedade, território urbano e natureza. Esta abordagem, na área urbana do Porto, de extrema importância prossegue na actualidade e estão em curso investigaçóes preliminares com o mesmo propósito na zona ribeirinha de Vila Nova de Gaia e área urbana envolvente.

\section{AGRADECIMENTOS}

Este trabalho recebeu o apoio da Fundação para a Ciência e a Tecnologia (FCT) e de fundos do FEDER através do projecto de I\&D GROUNDURBAN (POCI/CTE-GEX/ 159081/2004|FCT).

Um agradecimento especial às Prof. ${ }^{\text {as }}$ Inês Amorim e Helena Osswald (FLUP), e Prof. Martins de Carvalho (ISEP) pela sua disponibilidade em trocar ideias com os autores.

\section{REFERÊNCIAS BIBLIOGRÁFICAS}

Afonso, M. J., H. I. Chaminé, J. M. Carvalho, J. M. Marques, P. M. Carreira, L. Guimarães, L. Guilhermino, P. E. Fonseca, A. Gomes, M. Fonseca, A. Pires \& F. T. Rocha (2007a) 'Uma abordagem geoambiental no estudo dos subterrâneos da cidade do Porto:o caso do manancial de Paranhos'. In: Seminário sobre Águas Subterrâneas, LNEC, 1-2 de Março de 2007. Associação Portuguesa dos Recursos Hídricos (APRH), Lisboa, 10 p. (CD-Rom).

Afonso, M. J., I. H. Chaminé, M. J. Carvalho, M. J. Marques, A. Gomes, M. A. Araújo, P. E. Fonseca, J. Teixeira, M. A. M. d. Silva \& F. T. Rocha (2007b) 'Urban groundwater resources: a case study of Porto metropolitan area (Iberian Massif, NW Portugal)'. In: Ken W F Howard (ed). Urban Groundwater: Meeting the Challenge (Chapter 20 - Urban Aquifer Management). Selected Papers on Hydrogeology, IAH/Taylor \& Francis CRC Press, SP8, pp. 278 - 294.

Afonso, M. J. C. (2003) 'Hidrogeologia' de rochas graníticas da região do Porto (NW de Portugal). Cadernos Lab. Xeolóxico de Laxe, A Coruña, 28, pp. 173-192.

Amorim, A. A. \& J. N. Pinto. 2001. Porto d'agoa: o abastecimento de água à cidade do Porto através dos tempos. Porto: Serviços Municipalizados de Água e Saneamento, 196 p. 
Bocquet, D., K. Chatzis \& S. A. (2008) 'From free good to commodity: Universalizing the provision of water in Paris (1830-1930). Geoforum, 39, pp. 1821-1832.

Capela, J. V., Matos, H., Borralheiro, R. (2009) As freguesias do Distrito do Porto nas Memórias Paroquiais de 1758 Memórias, História e Património. Braga, 1038 p.

Carvalho, J. M. \& H.I.Chaminé (2007) Uma perspectiva sobre o valor acrescentado das Ciências da Terra nas indústrias do termalismo e do engarrafamento de água. In: Chaminé, H. I. \& Carvalho, J. M. (eds.), O valor acrescentado das Ciências da Terra no termalismo e no engarrafamento da água. Artigos seleccionados do II Fórum Ibérico de Águas Engarrafadas e Termalismo. DEG/LABCARGA, Instituto Superior de Engenharia do Porto, pp. 11-23.

Cordeiro, J. M. L. (1993) 'Um serviço Centenário: o abastecimento domiciliário de água à cidade do Porto (1887-1987). Arqueologia Industrial, 2a serie I (1-2), pp. 11 - 34.

Fontes, A. 1908. Contribuição para a hygiene do Porto: Analyse sanitária do seu abastecimento em agua potável I. Estudo dos Mananciais de Paranhos e Salgueiros. Dissertação inaugural apresentada à Escola MédicoCirúrgica do Porto. Typ. Encyclopedia Portugueza, Porto, 172 p.

Gavand, E. H. 1864. Estudo sobre o abastecimento d'agua da cidade do Porto Porto: Typ. Commercial, 143 p.

Geels, F. (2005) 'Co-evolution of tecnology and society: The transition in water supply and personal hygiene in the Netherlands (1850 - 1930) - a case study in multi-level perspective. Thecnology in Society, 27, pp. 363 - 397.

Jorge, R. 1888. Saneamento do Porto. Relatório apresentado à comissão municipal de saneamento. Typographia de Antonio José da Silva Teixeira, Porto, 110 p.

Júnior, A. d. A. 1895. Breves apontamentos sobre águas de poços do Porto. Dissertação Inaugural, Escola MédicoCirúrgica, Typografia Gandra, $65 \mathrm{p}$.

Junior, J. B. 1909. Contribuiçẫo para a hygiene do Porto: Analyse sanitaia do seu abastecimento em agua potavel. Porto: II - Mananciais do Campo Grande, Bispo e Freiras, Cavaca, Camóes, Virtudes, Fontaínhas, Praça do Marquês de Pombal e Burgal: fontes suas derivadas de nascente privativa. Dissertaçáo inaugural apresentada à Escola Médico-Cirúrgica do Porto. Typ. Encyclopedia Portugueza, Porto, 112 p.

Marçal, H. 1968. O abastecimento de água à cidade do Porto e à vila de Matosinhos. Separata do Boletim da Biblioteca Pública Municipal de Matosinhos, Tip. Leixôes, 15, 55 p. + estampas e plantas.

Marques, H., J. A. R. Fernandes \& L. P. Martins. 1990. Percursos nos espaços de memória. Porto: Afrontamento, 108 p.

Mena, J. C. 1908. Contribuição para o estudo da Hygiene do Porto: analyse sanitaria do seu abastecimento em água potável. . III. Estudo sobre os poços do Porto. Dissertação inaugural apresentada à Escola Médico-Cirúrgica do Porto. Typ.da Encyclopedia Portugueza, Porto, 270 pp.

Noronha, T. d. B. e. 1885. As aguas do Porto. Dissertação Inaugural à Escola Médico-Cirúrgica do Porto. Typ. Occidental, Porto, 89 p.

Oliveira, J. M. P. d. 1973. O espaço urbano do Porto - Condiçóes naturais e desenvolvimento. Lisboa. Instituto de Alta Cultura. 2a ed. fac-similada, 2007. Porto: Afrontamento, 496 p.

Ramos, L. A. O. 2000. História do Porto. Porto: Porto Editora, 720 p.

Reis, H. D. e. S. 1867. Mappa synoptico, estatístico, historico dos mananciaes publicos d'esta Antiga, mui Nobre, sempre Leal e Invicta Cidade do Porto. Códice 1295, BPMP

Serén, M. d. C. \& G. M. Pereira. 2000. 'O Porto Oitocentista'. in História do Porto, Dir. Luís A. de Oliveira Ramos, 1994 tirar, Porto Editora, pp. 377-521.

Silva, A. J. F. d. 1881. As Águas do Rio Souza e os Mananciais e Fontes da Cidade do Porto. Porto: Typographia Occidental, $24 \mathrm{p}$.

Silva, F. R. d. 1888. O Porto e o seu Termo, os homens, as instituiçōes e o poder (1580 - 1640). Porto: Câmara Municipal do Porto, $37 \mathrm{p}$.

Silva, G. d. 2000. Fontes e chafarizes do Porto. Porto: Serviços Municipalizados de Água e Saneamento do Porto, 244 p.

Tempelhoff, J., H. Hoag, M. Ertsen, E. Arnold, M. Bender, K. Berry, C. Fort, D. Pietz, M. Musemwa, M. Nakawo, J. Ur, P. v. Dam, M. Melosi, V. Winiwarter \& T. Wilkinson (2009) 'Where has the water come from? Water History, 1, pp. $1-8$.

\section{CARTOGRAFIA ANTIGA}

Balck, G. 1813. Cidade do Porto - Planta Redonda. Porto.

Clark, W. C. 1833. Oporto. Porto.

Ferreira, A. G. T. 1892. Carta Topográfica da Cidade do Porto. Porto.

Lima, C. 1839. Planta Topographica da Cidade do Porto. Lisboa.

Perry-Vidal. F. 1844. Planta da Cidade do Porto. Lisboa. 